\title{
Stochastic Multi-Criteria Acceptability Analysis for Technology Transfer Evaluation: A Case Study in Construction Digging
}

\author{
Amin Asadi Komleh \\ Department of Industrial Engineering \\ Mazandaran University of Science and Technology, Babol, Iran \\ Hamed Fazlollahtabar \\ Department of Industrial Engineering \\ School of Engineering, Damghan University, Damghan, Iran \\ Corresponding author: hfazl@du.ac.ir
}

(Accepted January 25, 2019; Received May 16, 2019)

\begin{abstract}
Technology selection and technology transfer are widely used in developing countries. Technology as a science of application of knowledge is simple or complex, personal or public, new or old. Technology transfer is a way to transmit skills, knowledge, production method, production samples and facilities among societies, universities and other communities. In order to ensure that technology and scientific progress can develop technology more in new production methods and applications, technology transfer is raised. This research focuses on a new paradigm for evaluating technology transfer in a construction tool in uncertain environment. For this purpose, technology and technology transfer has been explained. In this study, initially some effective technology transfer factors are collected by reviewing the related literature and then a multi-attribute decision aid has been used for incompleteness and vagueness issues. All identified factors were proposed in a questionnaire and surveyed by technology transfer experts to determine their impacts. A case study in construction field is conducted to verify the application of the decision aid model.
\end{abstract}

Keywords- Technology transfer, Stochastic multi-criteria acceptability analysis (SMAA), Technological cooperation, Digging tool.

\section{Introduction}

Increasing growth of technical knowledge in modern world and variety of needs have taken the opportunity from famous economical corporations to be individually able to provide all their needs including technical knowledge. Also, in some cases, direct entrance to all production fields is not economical. Nowadays, companies inevitably while accepting risk, provide some of their needs by cooperation with other companies or outside deputing scientific-oriented and technology producer companies. It is worthy to say that considering to role of technology in development and innovation, technology is commercializing day by day as a commodity by technology producer companies and has found its special market place in commerce and economy. However, technology may be provided by an internal or international process.

Life cycle of products is increasing by rapid development of technology. A company has to continue to develop new technology to differ from other countries and compete with them. Transfer of good technology may able a company to improve production efficiency, effectiveness and adaptability, unity, international development and stable competitive advantage. Transfer of technology includes a complicated process, which considers to complexity of technology, learning ownership, ability to access to learning and mutual effect between two sections. After 
International Journal of Mathematical, Engineering and Management Sciences

Vol. 4, No. 4, 1031-1039, 2019

https://dx.doi.org/10.33889/IJMEMS.2019.4.4-082

achieving necessary technology, buying company should change experimental knowledge managed and stored in the company to clear knowledge. All manufacturing productivity alliance efficiency and adapt ability depends on technology transfer (Cui et al., 2006).

Stochastic multivariable acceptability analysis (SMAA) is subset of multivariable complementary decision analysis (MCDA) which is used for solving imperfect and vague problems. SMAA methods are used in many real issues because; First, inverse scale distance is suitable for many group decision making issues where decision makers are not able or tend to provide useful information. Also, SMAA was used for descriptive information about acceptability of different approaches and this may help to decision makers to recognize common acceptable adaptive solutions; Second, SMAA supported incorrect or unreliable different types of modeling by possible distribution and by flexibility and general method.

In this research, we show that SMAA calculations are performed effectively by numerical methods for developing different decisions making including interactive process. Here, considering the uncertainty of factors effective on technology transfer, stochastic multivariable acceptability analysis (SMAA) is used for evaluating each factor.

\section{Review of Technology Transfer and Multi Attribute Decision Making}

Technology transfer is a process to transmit technology by a supplier to a receiver using different approaches to enhance the technological perspectives of a receiver, which happens among all sectors of industry, agriculture, mine, energy, health, etc. Technology could help to decrease production cost and increase manufacturing productivity by increasing of a firms activities (Gisselquist and Jean-Marie, 2000). Technology transfer involves strategic works in order to distribute information regarding innovative and considerably based practices to individuals, organizations, and communities and to help them to manage the challenges of using that ignorance to make. There are not any specific methodologies or framework to assess technology transfer. Reisman (2005) presented taxonomy and defined the technology transfer concept and its pillars.

Variety of researches has been investigated to point out effective factors and methods for technology commercialization and transfer from universities and public to companies (D'Este and Perkmann, 2011; Villani et al., 2017; Min et al., 2019). University technology transfer has emerged as an important and standalone research field over the past few decades. Given the great challenges that are involved with transferring science to the market, many universities have established technology transfer offices, science parks, incubators, and university venture funds an organizational assemblage labeled the technology transfer (TT) ecosystem (Good et al., 2019). In general, according to the reviewed researches, a systematic factor collection for an industrial technology transfer was not investigated. For technology selection and technology transfer evaluation with respect to various attributes, different methods were developed. Simple additive weighting (SAW) model is a simplest of multi attribute decision making (MADM) methods. With computing additives weights can used this method easily (Zionts and Wallenius, 1983).

TOPSIS is one of the best MADM models and it is of great use. In this model M alternative and $N$ criteria are evaluated and firstly developed by Hwang and Yoon (1981), Chen and Hwang (1992). This technique is placed on the belief that the selection should be closest to the positive ideal solution and the greatest distance with the ideal solution is negative (Hwang and Yoon, 
International Journal of Mathematical, Engineering and Management Sciences

Vol. 4, No. 4, 1031-1039, 2019

https://dx.doi.org/10.33889/IJMEMS.2019.4.4-082

1981). In this method, criteria and alternatives must exist otherwise this method fails to perform appropriately (Chen and Hwang 1992). TOPSIS has been also extended for group decision making (Huang and Li, 2012).

ELECTRE model in the late 1980s was raised and was considered as one of the best MADM techniques. Based on this concept not lead the rankings options but may omit options (Roy, 1968). MCDA will be used as it is considered most suitable for ELECTRE methods (Figueira et al., 2011). ELECTRE is appropriate to what is referred to as the choice problematic or problematic $\alpha$, where the objective is to select a smallest set of best alternatives. All ELECTRE methods belong to the family of outranking methods (Roy et al., 1992).

AHP is placed on analysis of the human brain and fuzzy been proposed for complex problems. This method was proposed in 1970. In paired comparisons questionnaire binary combination of all criteria and options should be considered So if the number is high standards and options can also increase the number of pairwise comparisons that it would prolong the questionnaire answers are wrong comparisons are possible Or impatience comparisons become of not fill carefully and inconsistency rate increase (Saaty, 1980). Its usage is highly extended in many areas, such as: technological investment evaluation (Boucher and MacStravic, 1991), analysis of financial parameters (Mandic et al., 2014), strategic planning (Yang and Ping, 2002), logisticS (Tyagi and Das, 1997), supplier selection (Ghodsypour and O'Brien, 1998; Deng et al., 2014), inventory classification (Lolli et al., 2014), internet access technology (Malladi and Min, 2005), IT project selection (Kearns, 2004) and even for reengineering of the health-care system.

Among all the MCDA techniques, no one considered stochastic uncertain occurrence and decision makers' opinion. Thus, we propose a technique to handle the drawbacks in industrial technology transfer evaluation.

\section{The Proposed Research}

Making suitable decision for technology transfer needs to experience and analysis of risk of success in technology transfer. In this research, importance of factors in technology transfer is evaluated by recognizing factors effective in technology transfer. Considering to uncertain factors, stochastic multivariable acceptability analysis (SMAA) is used which is from multivariable complementary decision analysis (MCDA) for solving imperfect and vague problems and information. Therefore, risk of success in technology transfer may be evaluated

\subsection{Stochastic Multi-Criteria Acceptability Analysis}

Stochastic multi-criteria acceptability analysis (SMAA) is a class of multiple criteria decisionaiding (MCDA) methods. There are various SMAA methods to handle the three main MCDA problem statements (Figueira et al., 2005): choosing, ranking, and sorting. Missing a value refers to incomplete information but Imprecise to information means that there is not required precise for the variable but not with the required precision. Uncertainty, instead, is a form of ignorance appearing when the observer is taken into account. It means that the observer gives complete and precise information, but is unreliable itself (consider Figueira et al., 2005). Up to now, selection of suitable method for technology transfer has been main issue of many researches. In this research, we are going to recognized factors effective in technology transfer and after evaluating importance of each factor in technology transfer and considering to uncertainty of factors, stochastic multivariable acceptability analysis (SMAA) is used and then risk of success in technology transfer in using Barad Khod Hafar digging device is evaluated. This method has 
International Journal of Mathematical, Engineering and Management Sciences

Vol. 4, No. 4, 1031-1039, 2019

https://dx.doi.org/10.33889/IJMEMS.2019.4.4-082

other advantages to already developed ones in addition to being hierarchical and having index. For example, SMAA method is based on possibility and uncertainty and acts based on data not view of decision makers.

\subsection{Methodology}

In this research, SMAA technique is used for evaluating factors using digging devices considering to uncertainty of factors effective in technology transfer.

Main questions of the research are as follows:

1- What are factors and scales effective in technology transfer?

2- How much is the risk of success in technology transfer?

3- How much is the importance of factors and scales?

A survey has been performed based on posted questionnaire in order to evaluate process of technology transfer. This research includes series of questions to which the managers should answer and the questions are related to them and their competitors. This questionnaire includes the following cases and the corresponding questions:

\section{Technical Factors}

1-How is the quality of device with self-drilling anchor in comparison with the other devices?

2- How is the reliability of device with self-drilling anchor in comparison with the other devices?

3 - How is the volume of device with self-drilling anchor in comparison with the other devices?

4- How is the flexibility of device with self-drilling anchor in comparison with the other devices?

\section{Financial Factors}

5- How is the capital of device with self-drilling anchor in comparison with the other devices?

6- How is the operation of device with self-drilling anchor in comparison with the other devices?

\section{Time Factors}

7-How is the cycle time of device with self-drilling anchor in comparison with the other devices?

\section{Cost Factors}

8- How is the cost of device with self-drilling anchor in comparison with the other devices? The responders have a 0 to 10 scale value to state their opinions for each question. 
International Journal of Mathematical, Engineering and Management Sciences

Vol. 4, No. 4, 1031-1039, 2019

https://dx.doi.org/10.33889/IJMEMS.2019.4.4-082

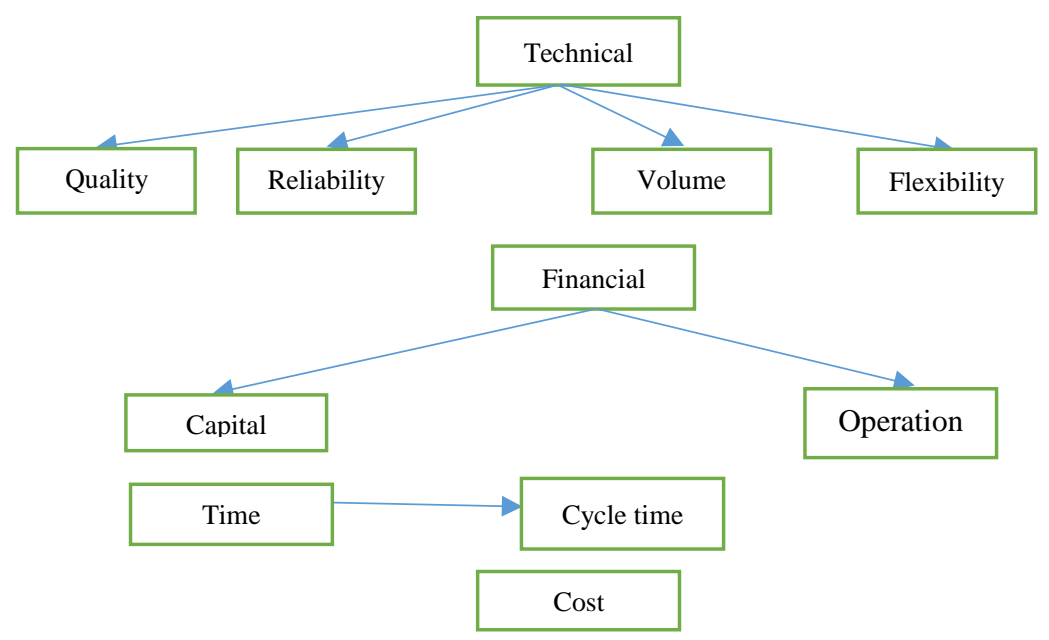

Figure 1. Technology transfer factors

As shown in the Figure 1, the addressed indicators are divided into four groups. This is done for facilitating evaluation of technology transfer considering to the specification mentioned in the literature. Flexibility, repeatability, volume, reliability, and quality are indicators which are placed in technical group by definition. Renewal, operation, selling, and capital are indicators which are placed in financial group. Also, cycle time and regeneration time are indicators of time group.

\section{1-Technical 2-Financial 3-Time 4-Cost}

\subsection{Acceptability Index}

It is computed as a multidimensional integral over the criteria distributions and the favorable weight space as

$a_{i}=\int_{\xi \in \chi} F_{\chi}(\xi) \int_{w \in W_{i}(\xi)} F_{w}(w) d w d \xi$

Acceptability indices can be used to classify alternatives into stochastically efficient or inefficient ones. A zero acceptability index means that an alternative is never considered the best with the assumed preference model.

\section{Case Study}

\subsection{Nailing Technology}

Nailing in soil includes insistent reinforcement of soil at place by installing non-prefabricated steel pillars at close distances (as a nail) that are enfolded by injecting grout. As nailing is progressed from up to down, shotcrete is performed for connection in face of artificial gable roof. Nailing in soil is generally used for stabling available gable roof or dibbling where performance if from up to down which is considered as important advantage comparing other guard systems. In definite conditions, nailing in soil is efficient substitution in terms of technical performance, 
International Journal of Mathematical, Engineering and Management Sciences

Vol. 4, No. 4, 1031-1039, 2019

https://dx.doi.org/10.33889/IJMEMS.2019.4.4-082

construction costs and performance time for ground anchor walls which are generally anchored from up to down.

\subsection{Data Collection}

Purposed population of this research includes engineering companies and construction contractors and advisers in Iran. Gopleh, Armno, Naghsh Jahan Pars, Arkandid and Tossee Ayandeh Pars companies were selected. Among 150 questionnaires, 144 questionnaires were usable. Most answerers had important management positions and were from organizations, which had more than 300 personnel.

\subsection{Results}

Analysis of data showed that most answerers had important management positions and were from organizations which had more than 300 personnel. The following table shows maximum and minimum grades of above questions. The answerers were asked to classify the questions by their importance. The limits for each question are shown in Table 1.

Table 1. The minimum and maximum scoring the questions

\begin{tabular}{|c|c|c|}
\hline Max & Min & Factor \\
\hline 7 & 5 & Quality \\
\hline 9 & 6 & Reliability \\
\hline 10 & 9 & Volume \\
\hline 10 & 6 & Capital \\
\hline 3 & 1 & Flexibility \\
\hline 10 & 9 & Operation \\
\hline 10 & 7 & Cycle time \\
\hline 4 & 1 & Cost \\
\hline
\end{tabular}

After output of questionnaire and gained numbers, we use continuous uniform distribution due to following reasons:

1- Type of questionnaire is spatial spectrum,

2- we don't have failure,

3- it is continuous,

4- it is the most efficient,

5- it is the most coincident so that $\mathrm{f}(\mathrm{x})$ is equal to:

$f(x)=\frac{1}{b-a}$

( $a$ is equal to lower limit or the lowest grade and $b$ is equal to upper limit or the highest grade).

Table 2 shows $F(x)$ after filling and grading experts, which has been gained for each factor. On the other hand, as range of questionnaire is between zero and ten, $W$ or $F(w)$ is preferred to be 0.1. Considering to $F(x)$ and $F(w)$ gained from each mentioned factor using Equation (1) and is shown in Table 2. 
International Journal of Mathematical, Engineering and Management Sciences

Vol. 4, No. 4, 1031-1039, 2019

https://dx.doi.org/10.33889/IJMEMS.2019.4.4-082

Table 2. Derived $F(x)$ from the Equation (2)

\begin{tabular}{|c|c|}
\hline $\mathrm{F}(\mathrm{x})$ & Factor \\
\hline $1 / 2$ & Quality \\
\hline $1 / 3$ & Reliability \\
\hline 1 & Volume \\
\hline $1 / 4$ & Capital \\
\hline $1 / 2$ & Flexibility \\
\hline 1 & Operation \\
\hline $1 / 3$ & Cycle time \\
\hline $1 / 4$ & Cost \\
\hline
\end{tabular}

After solving twofold integral, we sort the obtained values from the highest to the lowest as given in Table 3.

Table 3. Factors amounts

\begin{tabular}{|c|c|}
\hline $\mathrm{F}(\mathrm{x})$ & Factor \\
\hline 10 & Volume \\
\hline 10 & Operation \\
\hline 5 & Quality \\
\hline 5 & Flexibility \\
\hline $3 / 3$ & Reliability \\
\hline $3 / 3$ & Cycle time \\
\hline $2 / 5$ & Capital \\
\hline $2 / 5$ & Cost \\
\hline
\end{tabular}

As shown in the Table 3, four following factors gained the most grades respectively:

1-Volume 2-Operation 3-Flexibility 4-Quality

\section{Discussions and Conclusions}

Use of Barad Khod Hafar digging device is a more effective digging than other devices and development of these devices caused that tunnel progresses increase more considerable and also, increase efficiency of workers and their abilities. It also makes operation easier and has more flexibility than other devices. Finally, use of Khod Hafar digging device increases quality. Also, it is able to dig in hard geological lands. The considerable disadvantage of this device is its high expenditures. Statistics proved that Barad Khod Hafar digging devices, despite primary expense and more investment than other digging devices, are more efficient and are more economical. It may be certainly said that the only suitable digging solution is to use this digging method in some geological conditions. Better permeability rate of Barad Khod Hafar digging devices creates less expense of digging than other digging devices and in comparison with other digging systems, it has more permeability and better hole quality and less expenses in hard geological lands. Speed of digging and possibility of digging hole without deviation at hard conditions are special specifications of this device and considerable advantages of this system. Economically, it has higher price than other devices. But, due to speed of permeability and accuracy of digging at stone unsuitable geological conditions, ton amounts extracted by these devices have less expense than other digging devices. It is obvious that knowledge of experts and custodians of the state mines about modern digging devices make possibility of using these machineries in the state 
International Journal of Mathematical, Engineering and Management Sciences

Vol. 4, No. 4, 1031-1039, 2019

https://dx.doi.org/10.33889/IJMEMS.2019.4.4-082

mines. Undoubtedly, more interaction of executive engineers and experts of mines with companies pioneer in modern digging methods in the world and use of new digging machineries may result in more use of specialized manpower in mines from one hand and increase of production efficiency on the other hand.

\section{Conflict of Interest}

There is no conflict of interest for this research.

\section{Acknowledgement}

We appreciate the editor and the reviewers for their comments leading to strengthen the quality of the paper.

\section{References}

Boucher, T.O., \& MacStravic, E.L. (1991). Multiattribute evaluation within a present value framework and its relation to the analytic hierarchy process. The Engineering Economist, 37(1), 1-32.

Chen, S.J., \& Hwang, C.L. (1992). Fuzzy multiple attribute decision making methods. In Fuzzy Multiple Attribute Decision Making (pp. 289-486). Springer, Berlin, Heidelberg.

Cui, A.S., Griffith, D.A., Cavusgil, S.T., \& Dabic, M. (2006). The influence of market and cultural environmental factors on technology transfer between foreign MNCs and local subsidiaries: A Croatian illustration. Journal of World Business, 41(2), 100-111.

D’este, P., \& Perkmann, M. (2011). Why do academics engage with industry? The entrepreneurial university and individual motivations. The Journal of Technology Transfer, 36(3), 316-339.

Deng, X., Hu, Y., Deng, Y., \& Mahadevan, S. (2014). Supplier selection using AHP methodology extended by D numbers. Expert Systems with Applications, 41(1), 156-167.

Figueira, J., Greco, S. \& Ehrgott, M., (2005). Multiple criteria decision analysis: state of the art surveys (Vol. 78). Springer Science \& Business Media.

Figueira, J.R., Almeida-Dias, J., Matias, S., Roy, B., Carvalho, M.J., \& Plancha, C.E. (2011). Electre Tri-C, a multiple criteria decision aiding sorting model applied to assisted reproduction. International Journal of Medical Informatics, 80(4), 262-273.

Ghodsypour, S.H., \& O'Brien, C. (1998). A decision support system for supplier selection using an integrated analytic hierarchy process and linear programming. International Journal of Production Economics, 56-57, 199-212.

Gisselquist, D., \& Jean-Marie, G. (2000). An argument for deregulating the transfer of agricultural technologies to developing countries. The World Bank Economic Review, 14(1), 111-127.

Good, M., Knockaert, M., Soppe, B., \& Wright, M. (2019). The technology transfer ecosystem in academia. An organizational design perspective. Technovation, 82-83, 35-50.

Huang, Y.S. \& Li, W.H., (2012). A study on aggregation of TOPSIS ideal solutions for group decisionmaking. Group Decision and Negotiation, 21(4), 461-473.

Hwang, C.-L. \& Yoon, K., (1981). Lecture notes in economics and mathematical systems. Multiple objective decision making, methods and applications: a state-of-the-art survey, 164, Springer, Berlin, Heidelberg. 
International Journal of Mathematical, Engineering and Management Sciences

Vol. 4, No. 4, 1031-1039, 2019

https://dx.doi.org/10.33889/IJMEMS.2019.4.4-082

Kearns, G.S. (2004). A multi-objective, multi-criteria approach for evaluating IT investments: results from two case studies. Information Resources Management Journal, 17(1), 37-62.

Lolli, F., Ishizaka, A., \& Gamberini, R. (2014). New AHP-based approaches for multi-criteria inventory classification. International Journal of Production Economics, 156, 62-74.

Malladi, S., \& Min, K.J. (2005). Decision support models for the selection of internet access technologies in rural communities. Telematics and Informatics, 22(3), 201-219.

Mandic, K., Delibasic, B., Knezevic, S., \& Benkovic, S. (2014). Analysis of the financial parameters of Serbian banks through the application of the fuzzy AHP and TOPSIS methods. Economic Modelling, $43,30-37$.

Min, J.W., Vonortas, N.S., \& Kim, Y. (2019). Commercialization of transferred public technologies. Technological Forecasting and Social Change, 138, 10-20.

Reisman, A. (2005). Transfer of technologies: a cross-disciplinary taxonomy. Omega, 33(3), 189-202.

Roy, B., (1968). Classement et choix en présence de points de vue multiples. Revue française d'automatique, d'informatique et de recherche opérationnelle. Recherche opérationnelle, 2(1), 57-75.

Roy, B., Slowinski, R., \& Treichel, W. (1992). Multicriteria programming of water supply systems for rural areas $^{1}$. Journal of the American Water Resources Association, 28(1), 13-31.

Saaty, T.L., (1980). The analytic hierarchy process. McGraw-Hill, New York.

Tyagi, R., \& Das, C. (1997). A methodology for cost versus service trade-offs in wholesale locationdistribution using mathematical programming and analytic hierarchy process. Journal of Business Logistics, $18(2), 77$.

Villani, E., Rasmussen, E., \& Grimaldi, R. (2017). How intermediary organizations facilitate universityindustry technology transfer: a proximity approach. Technological Forecasting and Social Change, $114,86-102$.

Yang, J., \& Ping, S. (2002). Applying analytic hierarchy process in firm's overall performance evaluation: a case study in China. International Journal of Business, 7(1), 29.

Zionts, S., \& Wallenius, J. (1983). An interactive multiple objective linear programming method for a class of underlying nonlinear utility functions. Management Science, 29(5), 519-529. 